Article

\title{
The Inhibitory Activity of Anthraquinones against Pathogenic Protozoa, Bacteria, and Fungi and the Relationship to Structure
}

\author{
Mendel Friedman ${ }^{1, *}$, Alexander $\mathrm{Xu}^{2}{ }^{2}$, Rani Lee ${ }^{2} \mathbb{1}$, Daniel N. Nguyen ${ }^{2}$, Tina A. Phan ${ }^{2}$, \\ Sabrina M. Hamada ${ }^{2}$, Rima Panchel ${ }^{2}$, Christina C. Tam ${ }^{3}$, Jong H. Kim ${ }^{3} \mathbb{D}$, Luisa W. Cheng ${ }^{3}$ and \\ Kirkwood M. Land ${ }^{2}$ \\ 1 Healthy Processed Foods Research Unit, Agricultural Research Service, \\ United States Department of Agriculture, Albany, CA 94710, USA \\ 2 Department of Biological Sciences, University of the Pacific, Stockton, CA 95211, USA; \\ a_xu2@u.pacific.edu (A.X.); r_lee50@u.pacific.edu (R.L.); d_nguyen62@u.pacific.edu (D.N.N.); \\ t_phan18@u.pacific.edu (T.A.P.); s_hamada@u.pacific.edu (S.M.H.); r_panchel1@u.pacific.edu (R.P.); \\ kland@pacific.edu (K.M.L.) \\ 3 Foodborne Toxins Detection and Prevention Research Unit, Agricultural Research Service, \\ United States Department of Agriculture, Albany, CA 94710, USA; christina.tam@usda.gov (C.C.T.); \\ jongheon.kim@usda.gov (J.H.K.); luisa.cheng@usda.gov (L.W.C.) \\ * Correspondence: mendel.friedman@usda.gov; Tel.: +1-510-559-5615
}

Academic Editor: Simone Carradori

Received: 27 May 2020; Accepted: 2 July 2020; Published: 7 July 2020

\begin{abstract}
Plant-derived anthraquinones were evaluated in cell assays for their inhibitory activities against the parasitic protozoa Trichomonas vaginalis human strain G3 that causes the sexually transmitted disease trichomoniasis in women, Tritrichomonas foetus bovine strain D1 that causes sexually transmitted diseases in farm animals (bulls, cows, and pigs), Tritrichomonas foetus-like strain $\mathrm{C} 1$ that causes diarrhea in domestic animals (cats and dogs), and bacteria and fungi. The anthraquinones assessed for their inhibitory activity were anthraquinone, aloe-emodin (1,8-dihydroxy-3-hydroxymethylanthraquinone), anthrarufin (1,5-dihydroxyanthraquinone), chrysazin (1,8-dihydroxyanthraquinone), emodin (1,3,8-trihydroxy-6methylanthraquinone), purpurin (1,2,4-trihydroxyanthraquinone), and rhein (1,8-dihydroxy-3carboxyanthraquinone). Their activities were determined in terms of $\mathrm{IC}_{50}$ values, defined as the concentration that inhibits $50 \%$ of the cells under the test conditions and calculated from linear dose response plots for the parasitic protozoa, and zone of inhibition for bacteria and fungi, respectively. The results show that the different substituents on the anthraquinone ring seem to influence the relative potency. Analysis of the structure-activity relationships in protozoa indicates that the aloe-emodin and chrysazin with the highest biological activities merit further study for their potential to help treat the diseases in women and domestic and farm animals. Emodin also exhibited antifungal activity against Candida albicans. The suggested mechanism of action and the additional reported beneficial biological properties of anthraquinones suggest that they have the potential to ameliorate a broad spectrum of human diseases.
\end{abstract}

Keywords: Trichomonas vaginalis; Tritrichomonas foetus; cell assays; trichomoniasis; trichomonosis; anthraquinones; structure-activity relationships; inactivation; mechanisms; health benefits; research needs

\section{Introduction}

A number of plant species (including Rheum palmatum L., Cassia obtusifolia L., and multiple Rubia species) are reported to biosynthesize anthraquinone derivatives [1-3]. The biosynthesis of anthraquinones 
occurs via the polyketide and shikimic acid pathways [4]. Anthraquinones are aromatic compounds with a 9,10-dioxoanthracene core substituted in the two benzene rings with phenolic $\mathrm{OH}$ and aliphatic groups that have been reported to have beneficial biological properties. Figure 1 shows the structures of the seven compounds evaluated against trichomonads in the present study: anthraquinone; anthrarufin (1,5-dihydroxy-9,10-anthraquinone); chrysazin (1,8-dihydroxy-9,10-anthraquinone); purpurin (1,2,4trihydroxy-9-10-anthraquinone); emodin (1,3,8-trihydroxy-6-methyl-9,10-anthraquinone); aloe-emodin (1,8-dihydroxy-3-hydroxymethyl-9,10-anthraquinone), and rhein from the edible rhubarb plant. The structure of a new anthraquinone (lucidin-isopropyl ether) that has strong anti-Trichomonas vaginalis activity, recently isolated from the roots of Morinda panamensis Seem., is also shown in Figure 1 [5]. Anthraquinones occur naturally in the plant as glycosides, as illustrated in Figure 1 by the structures of sennoside and rhein-8-glucoside. It seems, however, that aglycones produced on removal of the carbohydrate side chains are used in many reported studies, including this one [6].

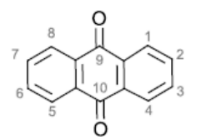

anthraquinone

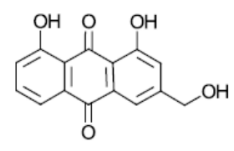

aloe-emodin
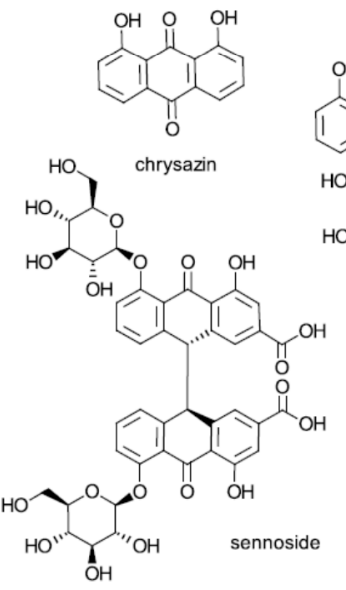

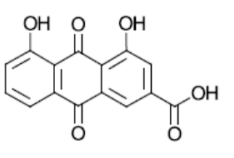

rhein

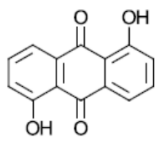

anthrarufin
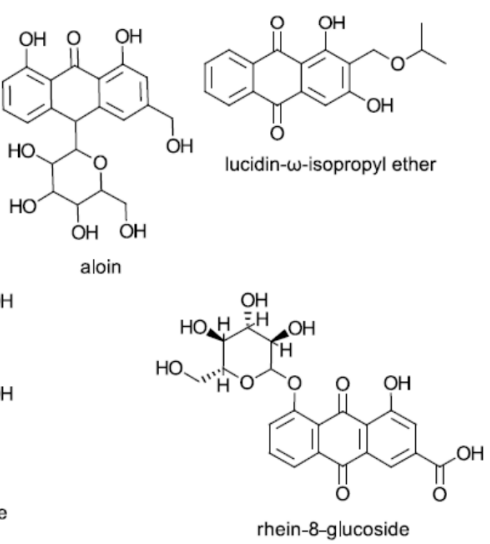

Figure 1. Chemical structures of anthraquinone and derivatives.

Interest in anthraquinones arises from the fact that they are reported to have multiple potential health benefits in cells and in vivo, including antibiotic [1,4,7,8], anticancer [2,9-11], antidiabetic [4], antifungal [12], anti-inflammatory [13], anti-obesity [14], antioxidative [13,15], antiprotozoal [16-18], antiviral [19], cardioprotective [20], hepatoprotective [21], and neuroprotective [22] properties. Emodin and aloe-emodin are already widely used as stimulant laxatives sold in pharmacies to treat constipation $[6,23,24]$.

Trichomonas vaginalis is the most common non-viral sexually transmitted human venereal disease that is most often detected in women and that does not appear to decrease with age, reaching a maximum rate in 48- to 51-year old women [25]. Tritrichomonas foetus protozoa strains cause the related sexually transmitted disease bovine trichomoniasis in cattle and pigs [26,27], and intestinal diarrhea in domestic cats and dogs [28-30]. The most cost-effective method to control the disease is often culling the infected animals. In domesticated cats, the disease is transmitted by the oral-fecal route where it infects the gastrointestinal tract, causing persistent diarrhea. Because drugs used to treat these diseases, 
such as metronidazole, show reduced potency because of resistance acquired by the pathogens [31], there is a need to develop new therapies [32].

We previously reported on the anti-oxidative and anti-inflammatory activities of four anthraquinones in chemical and cell assays [13] and on the anti-obesity properties of purpurin in mice on a high-fat diet [14]. In several publications related to the present study, we reported that the tomato glycoalkaloid tomatine [33], theaflavin-rich black tea extracts [34], potato-peel-containing glycoalkaloids and phenolic compounds [35] inhibited the growth of T. vaginalis human strain G3, T. foetus bovine strain D1, and T. foetus feline strain C1. We also reported that the potato peels and glycoalkaloids exhibited strong anti-obesity properties in mice on a high-fat diet [36].

In view of the bioactivities of anthraquinone compounds in cell assays and in vivo, and the anti-parasitic trichomonad properties of structurally different plant compounds, selected anthraquinones are investigated here for their ability to inhibit the growth of the three pathogenic trichomonad strains. This study aims, therefore, to use cell assays to compare the structure-activity relationships of the above-mentioned seven plant-derived anthraquinones against three parasitic protozoa strains that cause sexually transmitted diseases in humans, farm and domestic animals as well as some bacterial and fungal pathogens. The results suggest that the number, nature, and location of substituents on the anthraquinone moiety strongly influence their inhibitory potencies against the pathogenic protozoa and fungi.

\section{Results and Discussion}

The $\mathrm{IC}_{50}$ values (concentration that inhibits $50 \%$ of three pathogenic protozoa under the test conditions) were calculated from non-linear dose-response plots using the GraphPad software (San Diego, CA, USA) and as described previously [34].

The data in Table 1 show that, for $T$. vaginalis $\mathrm{G} 3$ (human), when comparing the lowest $\mathrm{IC}_{50}$ value (highest activity) for aloe emodin $(0.6109 \mu \mathrm{M})$ to the highest IC $_{50}$ value (lowest activity) for purpurin $(101.6 \mu \mathrm{M})$, aloe emodin has 166.2 times greater inhibitory activity than purpurin. Similar calculations of the ratios of the other compounds (compared to purpurin) using $\mathrm{IC}_{50}$ values shown in Table 1 indicate that rhein, chrysazin, and anthraquinone are $20.2,11.4$, and 9.8, respectively. The $\mathrm{IC}_{50}$ values for anthrarufin and emodin were not determined. The data show that for the human trichomonad, aloe-emodin exhibited the highest activity among the five evaluated compounds followed by chrysazin.

Table 1. Activity of anthraquinone and derivatives against pathogenic trichomonads. The table shows the calculated $\mathrm{IC}_{50}$ for each anthraquinone and substituted derivative and its corresponding percent growth inhibition at the designated concentration ${ }^{a}$.

\begin{tabular}{|c|c|c|c|c|c|c|c|c|c|}
\hline \multirow[b]{2}{*}{ Compound } & \multicolumn{3}{|c|}{ T. vaginalis G3 (human) } & \multicolumn{3}{|c|}{ T. foetus C1 (Feline) } & \multicolumn{3}{|c|}{ T. foetus D1 (Bovine) } \\
\hline & $\begin{array}{l}\mathrm{IC}_{50} \\
(\mu \mathrm{M})\end{array}$ & $\begin{array}{c}\text { Percent } \\
\text { Inhibition } \\
(\%)\end{array}$ & $\begin{array}{l}\text { Percent } \\
\text { Error } \\
(\%)\end{array}$ & $\begin{array}{l}\mathrm{IC}_{50} \\
(\mu \mathrm{M})\end{array}$ & $\begin{array}{c}\text { Percent } \\
\text { Inhibition } \\
(\%)\end{array}$ & $\begin{array}{c}\text { Percent } \\
\text { Error } \\
(\%)\end{array}$ & $\begin{array}{l}\mathrm{IC}^{50} \\
(\mu \mathrm{M})\end{array}$ & $\begin{array}{c}\text { Percent } \\
\text { Inhibition } \\
(\%)\end{array}$ & $\begin{array}{c}\text { Percent } \\
\text { Error } \\
(\%)\end{array}$ \\
\hline Purpurin & $101.60(1.0)^{b}$ & 51.2 & 2.5 & $133.10(1.0)$ & 50.29 & 0.59 & $78.62(1.0)$ & 49.64 & 0.72 \\
\hline Anthraquinone & $10.43(9.8)$ & 50.7 & 1.4 & $25.55(5.2)$ & 45.6 & 8.8 & $9.19(8.6)$ & 51.4 & 2.9 \\
\hline Anthrarufin & ND & ND & ND & $8.10(16.4)$ & 46.1 & 7.8 & 7.10(7.9) & 45.4 & 9.1 \\
\hline Chrysazin & $8.90(11.4)$ & 52.9 & 5.7 & $0.979(137.8)$ & 47.4 & 5.3 & $0.98(80.2)$ & 53.1 & 6.3 \\
\hline Aloe-Emodin & $0.6109(166.2)$ & 47.9 & 4.1 & $1.41(94.4)$ & 52.2 & 4.4 & $2.47(37.8)$ & 50.36 & 0.72 \\
\hline Emodin & ND & ND & ND & ND & ND & ND & $8.00(9.8)$ & 48.0 & 4.0 \\
\hline Rhein w/HPLC & $5.06(20.1)$ & 53.3 & 6.5 & $21.00(33.8)$ & 52.2 & 4.4 & $14.04(5.6)$ & 51.9 & 3.9 \\
\hline
\end{tabular}

${ }^{a}$ Compounds that did not show $>90 \%$ inhibition in preliminary screenings were not titrated (ND, not determined) for $\mathrm{IC}_{50}$ determination. All predicted IC50 values were re-tested and confirmed. Results shown were the average of three independent experiments with calculated percent error and $\mathrm{IC}_{50}$ values. ${ }^{b}$ Numbers in parenthesis are relative activities (potencies) in terms of $\mathrm{IC}_{50}$ values.

For the T. foetus (feline) strain, Table 1 shows that, in terms of $\mathrm{IC}_{50}$ value, chrysazin is 137.8 times more active than purpurin. The corresponding ratios (enhanced activities compared to purpurin) for 
aloe-emodin, rhein, anthrarufin, and anthraquinone are 94.4, 33.8, 16.4, and 5.2, respectively. The $\mathrm{IC}_{50}$ value for emodin was not determined. These data show that for the feline trichomonad strain, chrysazin shows the highest activity among the six evaluated compounds followed by aloe-emodin.

For the T. foetus (bovine), Table 1 shows that in terms of $\mathrm{IC}_{50}$ value, chrysazin is 80.2 times more active than purpurin. The corresponding values of enhanced activity for the five other compounds, aloe-emodin, emodin, anthraquinone, anthrarufin, and rhein, are 37.8, 9.8, 8.6, 7.9, 5.6, respectively. For the bovine trichomonad strain, chrysazin exhibited the highest activity and the enhanced activities of emodin, anthraquinone, anthrarufin, and rhein are in the narrow 9.8-5.6 range.

We evaluated anthraquinone and its six derivatives against a range of non-pathogenic bacteria, i.e., commensals such as Lactobacillus spp. and pathogenic bacteria especially, those relevant to foodborne pathogens in a disc diffusion assay. None of the compounds were inhibitory for bacterial growth at the tested concentrations as compared to the antibiotic controls (Table 2, Table 3).

Table 2. Table depicts the zones of inhibition in $\mathrm{mm}$ (growth inhibition) from a disc diffusion assay targeted against bacterial pathogens using DMSO vehicle control, antibiotic controls, and test compounds at indicated concentrations ${ }^{a, b} .{ }^{a}$ at $100 \mu \mathrm{M},{ }^{b}$ at $10 \mu \mathrm{M}$.

\begin{tabular}{ccccc}
\hline Compound & $\begin{array}{c}\text { Salmonella } \\
\text { Enterica }\end{array}$ & $\begin{array}{c}\text { Listeria } \\
\text { Monocytogenes }\end{array}$ & $\begin{array}{c}\text { Staphylococcus } \\
\text { Aureus }\end{array}$ & $\begin{array}{c}\text { Bacillus } \\
\text { Cereus }\end{array}$ \\
\hline DMSO & 0 & 0 & 0 & 0 \\
Levofloxacin $5 \mu \mathrm{g}$ & 30 & 17 & 36 & 26 \\
Gentamicin $10 \mu \mathrm{g}$ & 16 & 22 & 25 & 15 \\
Gentamicin $120 \mu \mathrm{g}^{a}$ & 22 & 30 & 30 & 20 \\
Purpurin $^{a}$ & 0 & 0 & 0 & 0 \\
Anthraquinone $^{a}$ & 0 & 0 & 0 & 0 \\
Anthrarufin $^{b}$ & 0 & 0 & 0 & 0 \\
Chrysazin $^{b}$ & 0 & 0 & 0 & 0 \\
Aloe-Emodin $^{b}$ & 0 & 0 & 0 & 0 \\
Emodin $^{b}$ & 0 & 0 & 0 & 0 \\
Rhein w/HPLC $^{b}$ & 0 & 0 & 0 \\
\hline
\end{tabular}

Table 3. Table depicts the zones of inhibition in $\mathrm{mm}$ (growth inhibition) from a disc diffusion assay targeted against bacterial commensals using DMSO vehicle control, antibiotic controls, and test compounds at indicated concentrations ${ }^{a, b} .^{a}$ at $100 \mu \mathrm{M},{ }^{b}$ at $10 \mu \mathrm{M}$.

\begin{tabular}{ccccc}
\hline Compound & $\begin{array}{c}\text { Escherichia coli } \\
\text { K12 }\end{array}$ & $\begin{array}{c}\text { Lactobacillus } \\
\text { Acidophilus }\end{array}$ & $\begin{array}{c}\text { Lactobacillus } \\
\text { Rhamnosus GG }\end{array}$ & $\begin{array}{c}\text { Lactobacillus } \\
\text { Reuteri }\end{array}$ \\
\hline DMSO & 0 & 0 & 0 & 0 \\
Levofloxacin $5 \mu \mathrm{g}$ & 30 & 0 & 15 & 5 \\
Gentamicin $10 \mu \mathrm{g}$ & 18 & 8 & 8 & 11 \\
Gentamicin $120 \mu \mathrm{g}^{\text {Rurpurin }}{ }^{a}$ & 20 & 15 & 15 & 20 \\
Anthraquinone $^{a}$ & 0 & 0 & 0 & 0 \\
Anthrarufin $^{b}$ & 0 & 0 & 0 & 0 \\
Chrysazin $^{b}$ & 0 & 0 & 0 & 0 \\
Aloe-Emodin $^{b}$ & 0 & 0 & 0 & 0 \\
Emodin $^{b}$ & 0 & 0 & 0 & 0 \\
Rhein w/HPLC $^{b}$ & 0 & 0 & 0 & 0 \\
\hline
\end{tabular}

To evaluate if anthraquinone or its six derivative compounds have any activity against fungal pathogens, an agar diffusion assay was used for two pathogenic fungi. Whereas the positive control compound octyl gallate was inhibitory for the growth of both A. fumigatus AF293 and C. albicans ATCC10231, only emodin was active against pathogenic fungi and specifically against Candida albicans (Table 4). 
Table 4. Activity of anthraquinone and derivatives against pathogenic fungi. The table shows the calculated zone of inhibition $(\mathrm{mm})$ for each anthraquinone and substituted derivative at the designated concentration $^{\mathrm{a}}$.

\begin{tabular}{cccc}
\hline Compound & $\begin{array}{c}\text { Concentration } \\
(\mathbf{m M})\end{array}$ & $\begin{array}{c}\text { A. fumigatus } \\
\text { AF293 }\end{array}$ & $\begin{array}{c}\text { C. albicans } \\
\text { ATCC10231 }\end{array}$ \\
\hline Aloin & 20 & 0.00 & 0.00 \\
\hline Purpurin & 20 & 0.00 & 0.00 \\
\hline Anthraquinone & 5 & 0.00 & 0.00 \\
\hline Anthrarufin & 5 & 0.00 & 0.00 \\
\hline Chrysazin & 5 & 0.00 & 0.00 \\
\hline Aloe-Emodin & 5 & 0.00 & 0.00 \\
\hline Emodin & 5 & 0.00 & $1.10(76 \%)^{\mathrm{c}}$ \\
\hline Octyl gallate & 5 & $1.15(100 \%)^{\mathrm{c}}$ & $1.45(100 \%)^{\mathrm{c}}$ \\
\hline DMSO & $50^{\mathrm{b}}$ & $0.00(0 \%)^{\mathrm{c}}$ & $0.00(0 \%)^{\mathrm{c}}$ \\
\hline
\end{tabular}

a Data shown were the average of duplicated results with calculated zone of inhibition values. ${ }^{\mathrm{b}}$ Percent $(\%)$ concentration; negative control. ${ }^{\mathrm{c}}$ Numbers in parenthesis (\%) are relative zone of inhibition compared to the positive control (octyl gallate), which is $100 \%$.

\subsection{Structure-Activity Relationships}

Tested against the $T$. vaginalis G3 strain, these data show that the introduction of three phenolic hydroxyl $(\mathrm{OH})$ groups into the 1, 2, 4 position of the right-hand benzene ring of the anthraquinone molecule (Figure 1) reduced activity because the anti-trichomonad activity of anthraquinone, which has no ring substituents, is 9.8-fold greater than that of purpurin, which has the three $\mathrm{OH}$ substituents. It seems that the three additional $\mathrm{OH}$ groups on purpurin resulted in an approximately 10-fold reduction in inhibitory activity. A similar enhancement of activity was observed with rhein, chrysazin, emodin, and aloe-emodin. The 166-fold enhanced activity of aloe-emodin compared to that of purpurin is striking. This compound contains two aromatic (phenolic) $\mathrm{OH}$ groups and one aliphatic hydroxymethyl $\mathrm{OH}$ group (Figure 1).

The structure-activity relationships for the other two trichomonad strains shown in Table 1 tend to parallel those of $T$. foetus strain C1, although the absolute enhancement values of all test compounds compared to purpurin differ somewhat. These observations suggest that there seems to be no direct relationships between the presence or absence of $\mathrm{OH}$ groups and relative activities.

The results with purpurin against the three trichomonads were unexpected and counterintuitive in view of the reported high activity of purpurin in numerous other biological activity studies highlighted below.

Table 1 shows, numerically, the trends of the active compounds at their respective $\mathrm{IC}_{50}$ values in relation to potencies and efficacy against the three pathogenic trichomonads. Significantly, similar growth inhibition values at $\mathrm{IC}_{50}$ values were obtained for each compound against the relevant trichomonad strain(s) tested. It would be of interest to determine if the in vitro results shown in Table 1 can be confirmed in vivo in farm and domestic animals and in humans.

\subsection{Antifungal Activity of Emodin}

None of the anthraquinone derivatives were effective against bacteria but emodin was selectively active against the yeast pathogen C. albicans at $5 \mathrm{mM}$. Percent zone of inhibition in C. albicans was determined as: 1) Negative control (DMSO only): 0\%, 2) emodin: 76\%, and 3) Positive control (Octyl gallate, $5 \mathrm{mM}$ ): $100 \%$, respectively. The growth of the filamentous fungal pathogen A. fumigatus was not affected by emodin at the same test concentration. 
The yeast pathogen C. albicans is one of the major agents causing human candidiasis, which includes vaginal infections. Yeast infection is continuously expanding globally due to the increased immune-compromised disorders [37]. While there have been seamless efforts to develop new antifungal drugs, current interventions have limited efficacy in treating fungal pathogens especially those resistant to conventional drugs [38]. Hence, the positive test with emodin warrants further clinical studies to confirm the beneficial in vitro results against $C$. albicans.

We found differential susceptibilities of the two pathogenic fungi (A. fumigatus, C. albicans) to growth inhibition by emodin. Of note, selective antifungal activity could also be found with the commercial antifungal drug fluconazole; the yeast pathogens Candida sp. and Cryptococcus sp. are susceptible to fluconazole, while the filamentous fungus $A$. fumigatus is not. This intrinsic resistance of A. fumigatus is linked to the naturally occurring T301I mutation in the cytochrome P450 enzyme gene encoding 14- $\alpha$ sterol demethylase A [39]. The precise determination of selective antifungal activity of emodin warrants future in-depth investigation.

\subsection{Biological Activities of Purpurin that Impact Human Health}

Purpurin has been reported to have numerous biological properties in cells and in rodents. These include the following observations. Tsang et al. [40] reported that purpurin inhibited Candida dubliniensis biofilm formation, suggesting that it has the potential to inactivate pathogenic fungi. The ability of purpurin to cross the blood-brain barrier and to ameliorate Alzheimer's-disease-like symptoms in mice suggests its potential to treat sufferers of this uncurable neurological disease [41]. The reported amelioration of anxiety- and stress-induced depressive effects in the brains of mice suggests that purpurin has the potential to reduce the effects of depression via a serotonergic mechanism [42]. The reported potent in vitro anti-adipogenic effects in adipocyte cells and in vivo anti-obesity effects in mice consuming a high-fat diet suggest that purpurin has the potential to serve as a human anti-obesity agent [14]. The observed inhibition of adipocyte-derived leucine aminopeptidase and angiogenesis in zebrafish suggests that purpurin could also act as a new angiogenic agent [43]. The potent anti-oxidative and anti-inflammatory properties of purpurin in chemical and macrophage cell assays suggest the compound might be able protect foods and cells against oxidative damage and prevent in vivo oxidative stress and inflammation [13]. The inhibition of linoleic acid peroxidation by purpurin (\% inhibition, concentration of purpurin): 84.8, $10 \mu \mathrm{M} ; 99.5,50 \mu \mathrm{M}$; and 97.7, $100 \mu \mathrm{M}$. These values are greater than observed by 3-tert-butyl-4-hydroxyanisole (BHA), a synthetic antioxidant used to protect foods such as soybean oil against peroxidation. The reported purpurin-induced inhibition of carcinogenic heterocyclic amines in vitro $[44,45]$ suggests that the molecule might also protect against the heat-induced formation of the carcinogens in cooked beef patties (hamburgers), an unsolved food safety issue described in detail elsewhere [46-48].

Some of these observations provide insights into the action of purpurin at the molecular-cellular level. The low anti-trichomonad activity of purpurin against the three strains observed here suggests that purpurin and the other evaluated anthraquinones act by unique mechanisms. Other studies that report on the antioxidant activities of anthraquinones in relation to their structure might provide insights into potential mechanisms of action of anthraquinones against trichomonads.

\subsection{Anti-Oxidative Properties of Anthraquinones}

Although we did not determine the antioxidative properties of the evaluated seven anthraquinones that might govern their anti-trichomonad mechanisms, it is instructive to mention reported relevant studies designed provide insight and to stimulate further needed studies. The relationship between the structure of a group of anthraquinones and their antioxidative activity was investigated by Nam, Kim, Nam and Friedman [13] in a study on the antioxidative and anti-inflammatory activities of four anthraquinones both in vitro and in cell assays: purpurin, (1,2,4-trihydroxyanthraquinone), anthrarufin (1,5-dihydroxyanthraquinone), chrysazin (1,8-dihydroanthraquinone), and anthraquinone, without $\mathrm{OH}$ substituents on the aromatic part of the molecule. Purpurin was the most active compound in 
all assays, as illustrated by the following micromolar $\mathrm{IC}_{50}$ values in the inhibition of the linoleic acid peroxidation assay: purpurin, 1.27 , anthrarufin, 23.5 , chrysazin, 202, and anthraquinone, 101 . These results show that purpurin, with the lowest $\mathrm{IC}_{50}$ value (highest activity), is 159 times more active than chrysazin, which had the lowest activity. These anthraquinones differ only in the number and location of the $\mathrm{OH}$ groups attached to the aromatic anthraquinone molecule, ranging from zero for anthraquinone to two for anthrarufin and chrysazin, and three for purpurin.

In a related study, Zengin et al. investigated the antioxidative effects of the following three anthraquinones: alizarin, quinizarin, and purpurin [49]. Purpurin showed the highest activity. On the basis of these and related cellular and biochemical studies, the authors suggest that the three anthraquinones may be used as antioxidants in foods and in medicine. A computational study of four anthraquinones (aloe-emodin, chrysophanol, emodin, and 1,3,8-trihydroxyanthraquinone) by Marković, Jeremić, Dimitrić Marković, Stanojević Pirković and Amić [15] describes the molecular mechanisms through which stable anthraquinone free radicals are formed by abstracting the reactive free electrons from reactive oxygen species (ROS) in cells or from oxidized food fatty acids [15]. The theoretical results are consistent with a mechanism that suggests that the overall geometry of the anthraquinones that might govern antioxidative capacity is greatly affected by mutual interactions among different substituents, resulting in the formation of unique structural conformations that can interact with active sites of cells. Elsewhere, we also describe the antioxidative mechanisms of phenolic compounds present in potatoes [50] and computer modelling methods involving interaction of phenolic $\mathrm{OH}$ groups with artificial cell membranes designed to elucidate the antibiotic mechanisms of black tea theaflavins and green tea chatechins [51,52].

The cited studies facilitate our understanding of the mechanisms that govern the antioxidative and antibiotic properties of the three classes of natural phenolic compounds-anthraquinones, potato phenolics, and tea molecules. It might be of interest to apply these molecular, cellular, and computational methods to define the anti-trichomonad properties of the seven anthraquinones evaluated in the present study. It would also be of interest compare anti-trichomonad and other biological effects of anthraquinone glycosides such as sennoside and rhein-8-gluoside (Figure 1) to the corresponding aglycones without the carbohydrate side chains [53].

\section{Materials and Methods}

\subsection{Materials}

Anthraquinone and six derivatives with different substituents on the aromatic ring were obtained from Sigma-Aldrich (St. Louis, MO, USA). Trichomonas vaginalis human strain G3 was from Patricia Johnson, University of California at Los Angeles, CA, USA, Tritrichomonas foetus feline strain D1 was from Lynette Corbeil at the University of California at San Diego, CA, USA, and feline Trichomonas foetus-like organism (strain C1) from Stanley Marks, University of California at Davis, School of Veterinary Medicine, CA, USA. The pathogenic and nonpathogenic bacteria and pathogenic fungi were obtained from the in-house United States of Agriculture (USDA) collection or from the American Type Culture Collection (ATCC, Manassas, VA, USA).

\subsection{Methods}

The powdered anthraquinones were used to determine their inhibitory activities against: (a) three parasitic trichomonad strains (human Trichomonas vaginalis G3, feline Tritrichomonas foetus-like C1, and bovine Tritrichomonas foetus D1); (b) four pathogenic bacteria (Salmonella enterica, Listeria monocytogenes, Staphylococcus aureus, and Bacillus cereus); (c) four nonpathogenic bacteria (E. coli $\mathrm{K} 12$ used as replacement for pathogenic E. coli, Lactobacillus acidophilus, Lactobacillus rhamnosus GG, and Lactobacillus reuteri); and (d) two pathogenic fungi (Aspergillus fumigatus and Candida albicans). 


\subsubsection{Stock Solutions of the Anthraquinone Powders}

The powders were dissolved in dimethyl sulfoxide (DMSO) to either $100 \mathrm{mM}$ (aloin and purpurin) or $10 \mathrm{mM}$ (anthraquinone, anthrarufin, aloe-emodin, emodin, and chrysazin). Solutions were prepared fresh and vortexed immediately before use.

\subsubsection{Trichomonad Growth Inhibition Assays}

Cultures of G3 strain of T. vaginalis and T. foetus $\mathrm{C} 1$ and D1 strains of were grown and maintained in $11 \mathrm{~mL}$ of TYM Diamond medium of $\mathrm{pH}$ 6.2. Every $24 \mathrm{~h}$, the cells from C1, D1, and G3 strains were passed by inoculating $1000 \mu \mathrm{L}$ of cells into a new $15 \mathrm{~mL}$ conical tube containing $10 \mathrm{~mL}$ of TYM Diamond medium. Then, the cells were incubated for $24 \mathrm{~h}$ at $37^{\circ} \mathrm{C}$. Inhibitory screens were carried out as previously described [33-35]. These assays were incubated at $37^{\circ} \mathrm{C}$ for $24 \mathrm{~h}$ before being counted using a hemocytometer. Percentage inhibitory activities were calculated relative to the dimethyl sulfoxide (DMSO control). Stock solutions were diluted in media and tested over a range of increasing concentrations. $\mathrm{IC}_{50}$ concentrations were calculated from using non-linear curve fitting on the GraphPad software (San Diego, CA, USA) and the predicted IC $_{50}$ concentration was confirmed by re-testing. All screening trials were performed a minimum of three times on three separate days to a standard error of $\leq 0.10$.

\subsubsection{Bacterial and Fungal Screens with Anthraquinone Compounds}

Anthraquinone derivatives were evaluated for their anti-bacterial in disc diffusion growth assays at $100 \mu \mathrm{M}$ (aloin and purpurin) or $10 \mu \mathrm{M}$ (anthraquinone, anthrarufin, aloe-emodin, emodin, and chrysazin) with the DMSO (negative control) diluted 1:1000 in media to have the same DMSO vehicle control concentration as the test powders. Positive controls for growth inhibition for the various bacteria were discs containing the following antibiotics: levofloxacin $5 \mu \mathrm{g}$, gentamicin $10 \mu \mathrm{g}$, and gentamicin $120 \mu \mathrm{g}$. None of the compounds had anti-bacterial activity at the concentrations tested. The antifungal activity of anthraquinone and its derivatives was examined in Aspergillus fumigatus AF293, a causative agent for invasive aspergillosis, and Candida albicans. Stock compounds were diluted to either $20 \mathrm{mM}$ (aloin and purpurin) or $5 \mathrm{mM}$ (anthraquinone, anthrarufin, aloe-emodin, emodin, and chrysazin) for fungi, respectively. DMSO was used as a negative vehicle control and $5 \mathrm{mM}$ octyl-gallate was used for the positive control for growth of both fungi. In both A. fumigatus and C. albicans tests, $5 \mu \mathrm{L}$ of anthraquinones were spotted onto the lawn of fungi (in duplicate), which were grown on Potato Dextrose Agar (PDA) or Yeast Peptone Dextrose (YPD; Bacto yeast extract 1\%, Bacto peptone $2 \%$, glucose $2 \%$ ) (Millipore Sigma, St. Louis, MO, USA) for A. fumigatus or C. albicans, respectively. Fungi were incubated at $35^{\circ} \mathrm{C}$ and the formation of zones of inhibition in millimeters $(\mathrm{mm})$ were monitored at 24 and $48 \mathrm{~h}$.

\section{Conclusions}

The evaluated test compounds were found to be active against the three parasitic protozoa; emodin also possessed antifungal activity against the yeast pathogen C. albicans. None of the compounds showed activity against pathogenic foodborne bacteria or lactobacilli. It seems, the nature and number of substituents on the anthraquinone ring were found to influence the wide-ranging relative potencies, as determined from $\mathrm{IC}_{50}$ values. In our previous study by Liu et al. [34], we reported on the $\mathrm{IC}_{50}$ values of the widely used drug metronidazole for each of the three trichomonads: T. vaginalis G3 = $0.72 \mu \mathrm{M} ;$ T. foetus $\mathrm{C} 1=0.55 \mu \mathrm{M} ;$ T. foetus $\mathrm{D} 1=0.49 \mu \mathrm{M}$. The data in Table 1 show that the corresponding values of aloe-emodin against the three trichomonads $\left(\mathrm{IC}_{50}=0.6109,1.41\right.$, and 2.47$)$ are of the same order of magnitude as those of metronidazole. Because of high rates of clinical resistance to the widely used synthetic drug metronidazole mentioned earlier, new approaches are needed to complement the available therapeutic treatments [32]. The most active anthraquinone compounds, aloe-emodin and chrysazin for T. vaginalis (human) and chrysazin and aloe-emodin against both the farm and domestic 
animal trichomonads, merit further study to define their ability to ameliorate both trichomoniasis in rodents [16] and humans [54,55] and trichomoniasis in farm and domestic animal against nonresistant as well as resistant trichomonad strains. In vivo animal and human studies should determine the ratio of effective to toxic doses. Finally, the results of the present anti-trichomonad studies and the cited studies by other investigators on health benefits of anthraquinones suggest that that this class of natural compounds has the potential to ameliorate multiple diseases.

Author Contributions: M.F., K.M.L., C.C.T., and J.H.K. designed the study. S.M.H., R.L., D.N.N., R.P., T.A.P., and A.X. performed the anti-parasite susceptibility assays. M.F., C.C.T., J.H.K., L.W.C., and K.M.L. analyzed the data and wrote the paper. All authors read and approved final manuscript.

Funding: M.F., C.C.T., L.W.C., and J.H.K. are funded by the United States Department of Agriculture-Agricultural Research Service. K.M.L. is funded by the Department of Biological Sciences, University of the Pacific.

Acknowledgments: We are most grateful to Carol E. Levin for creating Figure 1 and for facilitating the preparation of the manuscript.

Conflicts of Interest: The authors declare no conflict of interest.

\section{References}

1. Xu, J.S.; Cui, Y.; Liao, X.M.; Tan, X.B.; Cao, X. Effect of emodin on the cariogenic properties of Streptococcus mutans and the development of caries in rats. Exp. Ther. Med. 2014, 8, 1308-1312. [CrossRef] [PubMed]

2. Min, H.; Niu, M.; Zhang, W.; Yan, J.; Li, J.; Tan, X.; Li, B.; Su, M.; Di, B.; Yan, F. Emodin reverses leukemia multidrug resistance by competitive inhibition and downregulation of P-glycoprotein. PLoS ONE 2017, 12, e0187971. [CrossRef]

3. Dai, H.; Chen, Z.; Shang, B.; Chen, Q. Identification and quantification of four anthraquinones in rhubarb and its preparations by gas chromatography-mass spectrometry. J. Chromatogr. Sci. 2018, 56, 195-201. [CrossRef] [PubMed]

4. Chien, S.C.; Wu, Y.C.; Chen, Z.W.; Yang, W.C. Naturally occurring anthraquinones: Chemistry and therapeutic potential in autoimmune diabetes. Evid.-Based Complement. Altern. Med.: Ecam 2015, 2015, 357357. [CrossRef] [PubMed]

5. Cáceres-Castillo, D.; Pérez-Navarro, Y.; Torres-Romero, J.C.; Mirón-López, G.; Ceballos-Cruz, J.; Arana-Argáez, V.; Vázquez-Carrillo, L.; Fernández-Sánchez, J.M.; Alvarez-Sánchez, M.E. Trichomonicidal activity of a new anthraquinone isolated from the roots of Morinda panamensis Seem. Drug Dev. Res. 2019, 80, 155-161. [CrossRef] [PubMed]

6. Meier, N.; Meier, B.; Peter, S.; Wolfram, E. In-silico UHPLC method optimization for aglycones in the herbal laxatives Aloe barbadensis Mill., Cassia angustifolia vahl pods, Rhamnus frangula L. Bark, Rhamnus purshianus DC. bark, and Rheum palmatum L. roots. Molecules 2017, 22, 1838. [CrossRef]

7. Jafer, M.; Patil, S.; Hosmani, J.; Bhandi, S.H.; Chalisserry, E.P.; Anil, S. Chemical plaque control strategies in the prevention of biofilm-associated oral diseases. J. Contemp. Dent. Pract. 2016, 17, 337-343.

8. Ji, X.; Liu, X.; Peng, Y.; Zhan, R.; Xu, H.; Ge, X. Comparative analysis of methicillin-sensitive and resistant Staphylococcus aureus exposed to emodin based on proteomic profiling. Biochem. Biophys. Res. Commun. 2017, 494, 318-324. [CrossRef]

9. Li, Y.; Jiang, J.G. Health functions and structure-activity relationships of natural anthraquinones from plants. Food Funct. 2018, 9, 6063-6080. [CrossRef]

10. Chen, H.; Zhao, C.; He, R.; Zhou, M.; Liu, Y.; Guo, X.; Wang, M.; Zhu, F.; Qin, R.; Li, X. Danthron suppresses autophagy and sensitizes pancreatic cancer cells to doxorubicin. Toxicol. Vitr.: Int. J. Publ. Assoc. Bibra 2019, 54, 345-353. [CrossRef]

11. Yang, L.; Lin, S.; Kang, Y.; Xiang, Y.; Xu, L.; Li, J.; Dai, X.; Liang, G.; Huang, X.; Zhao, C. Rhein sensitizes human pancreatic cancer cells to EGFR inhibitors by inhibiting STAT3 pathway. J. Exp. Clin. Cancer Res.: Cr 2019, 38, 31. [CrossRef]

12. Janeczko, M.; Maslyk, M.; Kubinski, K.; Golczyk, H. Emodin, a natural inhibitor of protein kinase CK2, suppresses growth, hyphal development, and biofilm formation of Candida albicans. Yeast (Chichesterengland) 2017, 34, 253-265. [CrossRef] [PubMed] 
13. Nam, W.; Kim, S.P.; Nam, S.-H.; Friedman, M. Structure-antioxidative and anti-inflammatory activity relationships of purpurin and related anthraquinones in chemical and cell assays. Molecules 2017, 22, 265. [CrossRef] [PubMed]

14. Nam, W.; Nam, S.H.; Kim, S.P.; Levin, C.; Friedman, M. Anti-adipogenic and anti-obesity activities of purpurin in 3T3-L1 preadipocyte cells and in mice on a high-fat diet. BMC Complement. Altern. Med. 2019, 19, 364. [CrossRef] [PubMed]

15. Marković, Z.; Jeremić, S.; Dimitrić Marković, J.; Stanojević Pirković, M.; Amić, D. Influence of structural characteristics of substituents on the antioxidant activity of some anthraquinone derivatives. Comput. Theor. Chem. 2016, 1077, 25-31. [CrossRef]

16. Wang, H.-H. Antitrichomonal action of emodin in mice. J. Ethnopharmacol. 1993, 40, 111-116.

17. Dalimi, A.; Delavari, M.; Ghaffarifar, F.; Sadraei, J. In vitro and in vivo antileishmanial effects of aloe-emodin on Leishmania major. J. Tradit. Complement. Med. 2015, 5, 96-99. [CrossRef]

18. Kumar, S.; Yadav, M.; Yadav, A.; Rohilla, P.; Yadav, J.P. Antiplasmodial potential and quantification of aloin and aloe-emodin in Aloe vera collected from different climatic regions of India. BMC Complement. Altern. Med. 2017, 17, 369. [CrossRef]

19. Zhong, T.; Zhang, L.Y.; Wang, Z.Y.; Wang, Y.; Song, F.M.; Zhang, Y.H.; Yu, J.H. Rheum emodin inhibits enterovirus 71 viral replication and affects the host cell cycle environment. Acta Pharmacol. Sin. 2017, 38, 392-401. [CrossRef]

20. Bai, Y.; Su, Z.; Sun, H.; Zhao, W.; Chen, X.; Hang, P.; Zhu, W.; Du, Z. Aloe-emodin relieves high-fat diet induced QT prolongation via MiR-1 inhibition and IK1 up-regulation in rats. Cell. Physiol. Biochem.: Int. J. Exp. Cell. Physiol. Biochem. Pharmacol. 2017, 43, 1961-1973. [CrossRef]

21. Bu, T.; Wang, C.; Meng, Q.; Huo, X.; Sun, H.; Sun, P.; Zheng, S.; Ma, X.; Liu, Z.; Liu, K. Hepatoprotective effect of rhein against methotrexate-induced liver toxicity. Eur. J. Pharmacol. 2018, 834, 266-273. [CrossRef] [PubMed]

22. Li, X.; Chu, S.; Liu, Y.; Chen, N. Neuroprotective effects of anthraquinones from rhubarb in central nervous system diseases. Evid.-Based Complement. Altern. Med.: Ecam 2019, 2019, 3790728. [CrossRef] [PubMed]

23. Prasad, C.; Nurko, S.; Borovoy, J.; Korson, M.S. The importance of gut motility in the metabolic control of propionic acidemia. J. Pediatrics 2004, 144, 532-535. [CrossRef] [PubMed]

24. Zheng, Y.F.; Liu, C.F.; Lai, W.F.; Xiang, Q.; Li, Z.F.; Wang, H.; Lin, N. The laxative effect of emodin is attributable to increased aquaporin 3 expression in the colon of mice and HT-29 cells. Fitoterapia 2014, 96, 25-32. [CrossRef] [PubMed]

25. Stemmer, S.M.; Mordechai, E.; Adelson, M.E.; Gygax, S.E.; Hilbert, D.W. Trichomonas vaginalis is most frequently detected in women at the age of peri-/premenopause: An unusual pattern for a sexually transmitted pathogen. Am. J. Obstet. Gynecol. 2018, 218, 328.e1-328.e13. [CrossRef]

26. Okafor, C.C.; Strickland, L.G.; Jones, B.M.; Kania, S.; Anderson, D.E.; Whitlock, B.K. Prevalence of Tritrichomonas foetus in Tennessee bulls. Vet. Parasitol. 2017, 243, 169-175. [CrossRef]

27. Michi, A.N.; Favetto, P.H.; Kastelic, J.; Cobo, E.R. A review of sexually transmitted bovine trichomoniasis and campylobacteriosis affecting cattle reproductive health. Theriogenology 2016, 85, 781-791. [CrossRef]

28. Gookin, J.L.; Hanrahan, K.; Levy, M.G. The conundrum of feline Trichomonosis. J. Feline Med. Surg. 2017, 19, 261-274. [CrossRef]

29. Paul, A.; Stayt, J. The intestinal microbiome in dogs and cats with diarrhoea as detected by a faecal polymerase chain reaction-based panel in Perth, Western Australia. Aust. Vet. J. 2019, 97, 418-421. [CrossRef]

30. Arranz-Solis, D.; Pedraza-Diaz, S.; Miro, G.; Rojo-Montejo, S.; Hernandez, L.; Ortega-Mora, L.M.; Collantes-Fernandez, E. Tritrichomonas foetus infection in cats with diarrhea from densely housed origins. Vet. Parasitol. 2016, 221, 118-122. [CrossRef]

31. Bradic, M.; Warring, S.D.; Tooley, G.E.; Scheid, P.; Secor, W.E.; Land, K.M.; Huang, P.-J.; Chen, T.-W.; Lee, C.-C.; Tang, P.; et al. Genetic indicators of drug resistance in the highly repetitive genome of Trichomonas vaginalis. Genome Biol. Evol. 2017, 9, 1658-1672. [CrossRef] [PubMed]

32. Eisinger, R.W.; Erbelding, E.; Fauci, A.S. Refocusing research on sexually transmitted infections. J. Infect. Dis. 2019, jiz442. [CrossRef] [PubMed]

33. Liu, J.; Kanetake, S.; Wu, Y.-H.; Tam, C.; Cheng, L.W.; Land, K.M.; Friedman, M. Anti-protozoal effects of the tomato tetrasaccharide glycoalkaloid tomatine and the aglycone tomatidine on mucosal trichomonads. J. Agric. Food Chem. 2016, 64, 8806-8810. [CrossRef] [PubMed] 
34. Noritake, S.M.; Liu, J.; Kanetake, S.; Levin, C.E.; Tam, C.; Cheng, L.W.; Land, K.M.; Friedman, M. Phytochemical-rich foods inhibit the growth of pathogenic trichomonads. BMC Complementary Altern. Med. 2017, 17, 461. [CrossRef]

35. Friedman, M.; Huang, V.; Quiambao, Q.; Noritake, S.; Liu, J.; Kwon, O.; Chintalapati, S.; Levin, C.E.; Tam, C.; Cheng, L.W.; et al. Potato peels and their bioactive glycoalkaloids and phenolic compounds inhibit the growth of pathogenic trichomonads. J. Agric. Food Chem. 2018, 66, 7942-7947. [CrossRef]

36. Elkahoui, S.; Bartley, G.E.; Yokoyama, W.H.; Friedman, M. Dietary supplementation of potato peel powders prepared from conventional and organic russet and nonorganic gold and red potatoes reduces weight gain in mice on a high-fat diet. J. Agric. Food Chem. 2018, 66, 6064-6072. [CrossRef]

37. Sobel, J.D.; Wiesenfeld, H.C.; Martens, M.; Danna, P.; Hooton, T.M.; Rompalo, A.; Sperling, M.; Livengood, C.; Horowitz, B.; Von Thron, J.; et al. Maintenance fluconazole therapy for recurrent vulvovaginal candidiasis. N. Engl. J. Med. 2004, 351, 876-883. [CrossRef]

38. Beardsley, J.; Halliday, C.L.; Chen, S.C.-A.; Sorrell, T.C. Responding to the emergence of antifungal drug resistance: Perspectives from the bench and the bedside. Future Microbiol. 2018, 13, 1175-1191. [CrossRef]

39. Leonardelli, F.; Macedo, D.; Dudiuk, C.; Cabeza, M.S.; Gamarra, S.; Garcia-Effron, G. Aspergillus fumigatus intrinsic fluconazole resistance is due to the naturally occurring T301I substitution in Cyp51Ap. Antimicrob Agents Chemother. 2016, 60, 5420-5426. [CrossRef]

40. Tsang, P.W.; Wong, A.P.; Yang, H.P.; Li, N.F. Purpurin triggers caspase-independent apoptosis in Candida dubliniensis biofilms. PLoS ONE 2013, 8, e86032. [CrossRef]

41. Viswanathan, G.K.; Shwartz, D.; Losev, Y.; Arad, E.; Shemesh, C.; Pichinuk, E.; Engel, H.; Raveh, A.; Jelinek, R.; Cooper, I.; et al. Purpurin modulates Tau-derived VQIVYK fibrillization and ameliorates Alzheimer's disease-like symptoms in animal model. Cell. Mol. Life Sci. 2019, 77, 2795-2813. [CrossRef] [PubMed]

42. Ma, L.; Hu, P.; Zhang, J.; Cui, W.; Zhao, X. Purpurin exerted antidepressant-like effects on behavior and stress axis reactivity: Evidence of serotonergic engagement. Psychopharmacology 2020, 237, 887-899. [CrossRef]

43. Park, H.; Shim, J.S.; Kim, B.S.; Jung, H.J.; Huh, T.-L.; Kwon, H.J. Purpurin inhibits adipocyte-derived leucine aminopeptidase and angiogenesis in a zebrafish model. Biochem. Biophys. Res. Commun. 2014, 450, 561-567. [CrossRef] [PubMed]

44. Takahashi, E.; Fujita, K.; Kamataki, T.; Arimoto-Kobayashi, S.; Okamoto, K.; Negishi, T. Inhibition of human cytochrome P450 1B1, 1A1 and 1A2 by antigenotoxic compounds, purpurin and alizarin. Mutat. Res. 2002, 508, 147-156. [CrossRef]

45. Takahashi, E.; Arimoto, S.; Okamoto, K.; Negishi, T. Enhancement of phase II enzyme activity by purpurin resulting in the suppression of MeIQx-DNA-adduct formation in mice. Mutat. Res. 2007, 626, 128-134. [CrossRef]

46. Friedman, M.; Zhu, L.; Feinstein, Y.; Ravishankar, S. Carvacrol facilitates heat-induced inactivation of Escherichia coli O157:H7 and inhibits formation of heterocyclic amines in grilled ground beef patties. J. Agric. Food Chem. 2009, 57, 1848-1853. [CrossRef]

47. Rounds, L.; Havens, C.M.; Feinstein, Y.; Friedman, M.; Ravishankar, S. Plant extracts, spices, and essential oils inactivate Escherichia coli O157:H7 and reduce formation of potentially carcinogenic heterocyclic amines in cooked beef patties. J. Agric. Food Chem. 2012, 60, 3792-3799. [CrossRef]

48. Rounds, L.; Havens, C.M.; Feinstein, Y.; Friedman, M.; Ravishankar, S. Concentration-dependent inhibition of Escherichia coli O157:H7 and heterocyclic amines in heated ground beef patties by apple and olive extracts, onion powder and clove bud oil. Meat Sci. 2013, 94, 461-467. [CrossRef]

49. Zengin, G.; Degirmenci, N.S.; Alpsoy, L.; Aktumsek, A. Evaluation of antioxidant, enzyme inhibition, and cytotoxic activity of three anthraquinones (alizarin, purpurin, and quinizarin). Hum. Exp. Toxicol. 2016, 35, 544-553. [CrossRef]

50. Friedman, M. Chemistry, biochemistry, and dietary role of potato polyphenols. A review. J. Agric. Food Chem. 1997, 45, 1523-1540. [CrossRef]

51. Sirk, T.W.; Brown, E.F.; Sum, A.K.; Friedman, M. Molecular dynamics study on the biophysical interactions of seven green tea catechins with lipid bilayers of cell membranes. J. Agric. Food Chem. 2008, 56, 7750-7758. [CrossRef]

52. Sirk, T.W.; Friedman, M.; Brown, E.F. Molecular binding of black tea theaflavins to biological membranes: Relationship to bioactivities. J. Agric. Food Chem. 2011, 59, 3780-3787. [CrossRef] [PubMed] 
53. Le, J.; Zhang, X.; Jia, W.; Zhang, Y.; Luo, J.; Sun, Y.; Ye, J. Regulation of microbiota-GLP1 axis by sennoside A in diet-induced obese mice. Acta Pharm. Sin. B 2019, 9, 758-768. [CrossRef]

54. Sgibnev, A.; Kremleva, E. Probiotics in addition to metronidazole for treatment Trichomonas vaginalis in the presence of BV: A randomized, placebo-controlled, double-blind study. Eur. J. Clin. Microbiol. Infect. Dis. 2020, 39, 345-351. [CrossRef] [PubMed]

55. Abdali, K.; Jahed, L.; Amooee, S.; Zarshenas, M.; Tabatabaee, H.; Bekhradi, R. Comparison of the effect of vaginal Zataria multiflora cream and oral metronidazole pill on results of treatments for vaginal infections including trichomoniasis and bacterial vaginosis in women of reproductive age. Biomed. Res. Int. 2015, 2015, 683640. [CrossRef] [PubMed]

Sample Availability: Samples of the compounds are not available from the authors. They can be purchased from chemical companies directly.

(C) 2020 by the authors. Licensee MDPI, Basel, Switzerland. This article is an open access article distributed under the terms and conditions of the Creative Commons Attribution (CC BY) license (http://creativecommons.org/licenses/by/4.0/). 